\title{
A Legação brasileira em Berlim (1931-1935): o cotidiano diplomático em um país em transformação
}

\author{
The Brazilian Legation in Berlin (1931-1935): the \\ Diplomatic Working Day in a country in transition \\ Peter Johann Mainka*
}

\author{
Palavras-chave: \\ Diplomacia Brasileira \\ Relações Exteriores \\ Itamaraty
}

Keywords:

Brazilian Diplomacy

International Relations

Itamaraty

\begin{abstract}
Resumo: Desde o século XVI a história do Brasil e a da Alemanha são relacionadas, apresentando paralelas, convergências e conexões (pessoais). Na década de 1930, os dois países passaram por transformações políticas profundas, que resultaram no estabelecimento de novos governos nos dois países - governos nacionalistas, autoritários e anticomunistas. Com base nesses valores compartilhados e em uma base ideológica semelhante, o Brasil e a Alemanha estiveram, na década de 1930, ainda mais próximos um para o outro. Essa proximidade e a simpatia mútua manifestamse também na atuação da Legação brasileira em Berlim, cujos registros no Arquivo Histórico do Itamaraty no Rio de Janeiro são a base documental deste artigo.
\end{abstract}

\begin{abstract}
Since the 16th century Brazilian and German history are linked by similarities, convergences and (personal) connections. In the 1930s, the two countries experienced extensive political transformations, which lead to the establishment of new governments in both countries - nationalist, authoritarian and anticommunist governments. Based on those shared values and a similar ideological base, Brazil and Germany were related even closer to each other in the 1930s. This mutual proximity and sympathy also manifests itself in the action of the Brazilian legation in Berlin, whose registers in the Historic Archive of the Itamaraty in Rio de Janeiro form the documental base of this paper.
\end{abstract}

Recebido em 04 de setembro de 2018. Aprovado em 11 de fevereiro de 2019.

\section{Introdução}

O início da década de 1930 trouxe mudanças políticas profundas tanto para o Brasil como para a Alemanha. No Brasil, a "Revolução de 1930", eclodida no dia 3 de outubro de 1930, pôs fim à denominada política do café com leite uma sequência de presidentes dos estados de São Paulo e Minas Gerais. Dessa forma, o candidato Getúlio Vargas (1882-1954), do Rio Grande do Sul, que havia sido derrotado nas eleições, conseguiu usurpar a presidência do Brasil por meio de um levante armado em novembro de 1930 (FAUSTO, 1982).

Entre as múltiplas causas dessa revolução, estavam desejos e reivindicações de uma renovação nacional do Brasil, ou seja, de uma política de nacionalização que determinou, nos próximos anos, também a política do governo de Getúlio Vargas em relação à imigração e aos imigrantes (HARMSBALTZER, 1970). Logo o governo de Getúlio Vargas foi impelido pela Revolução Constitucionalista, a assim chamada Guerra Paulista de 1932 (FEIJÓ; GERTEL, 1998), a conceder a convocação de uma Assembleia Constituinte que promulgou, no dia 16 de julho de 1934, a nova constituição. Apesar dessa constitucionalização do seu governo, Getúlio Vargas defendeu uma política autoritária, anticomunista e, às vezes, fascista, orientada no modelo italiano, para consolidar o seu próprio poder. Isso ficou mais nítido com a instauração do Estado Novo (19371945) por um segundo golpe e com o combate

* Professor da Julius-Maximilians-Universität Würzburg (JMUW) - Alemanha, professor visitante na Universidade Federal de Santa Catarina (UFSC) - Brasil. Mestre e doutor pela JMUW. E-mail: <peter.mainka@uni-wuerzburg.de>. 
exacerbado a movimentos políticos de oposição que questionaram a sua liderança, tais como a Intentona Comunista de 1935 (GOMES, 1992) e o Levante Integralista de 1938 (BERTONHA, 2016).

Sob essas condições gerais e em toda a consonância com o lema da bandeira brasileira, ordem e progresso, realizou-se na era Getúlio Vargas uma modernização abrangente de cima, no Estado, na economia e na sociedade do Brasil. Assim, houve uma centralização das estruturas estatais e uma nacionalização da sociedade e da economia do Brasil (MAINKA, 2008, p. 38-44).

$\mathrm{Na}$ Alemanha, nesse mesmo período, vigorava a democracia da República de Weimar, sucessora do (Segundo) Império Alemão (18711918), que havia provocado a eclosão da Primeira Guerra Mundial (1914-1918). Todos os males que a derrota da guerra, as determinações nem sempre equilibradas do Tratado de Paz de Versalhes (19191920) e a crise política e econômica trouxeram para a Alemanha pós-guerra (WINKLER, 1993) foram suportados pelo regime democrático. Nesse clima de mudanças e incertezas, a jovem democracia, hostilizada desde o início, não conseguiu defenderse contra as ofensas ideológicas dos extremos e, nomeadamente, do Partido Nacional-Socialista dos Trabalhadores Alemães (NSDAP) e do seu autonomeado Führer, Adolf Hitler (1889-1945).

Os últimos governos da República de Weimar, a partir de 1930, não mais foram apoiados por uma maioria parlamentar, mas pelo presidente marechal Paul von Hindenburg (1847-1934) partidário da monarquia e inimigo declarado da democracia -, que viabilizou um governo por medidas provisórias presidenciais. Sob essas condições gerais, Adolf Hitler conseguiu, no dia 30 de janeiro de 1933, ser nomeado chanceler, formar um governo e consolidar, consequentemente, o poder nacional-socialista na Alemanha, transformando a República de Weimar em uma ditadura e em um regime nazista (BRACHER, 1974; WINKLER, 1993; MAINKA, 2008).

De certa forma, o Brasil e a Alemanha encontravam-se, no início da década de 1930, em uma situação semelhante: governos recém-chegados ao poder, uma ideologia nacionalista, anticomunista e autoritária, e uma política de modernização de Estado, economia e sociedade. Essa proximidade ideológica e certa simpatia pela política do outro regime são percebidas na documentação da Legação brasileira em Berlim, na Alemanha, no início da década de 1930.

\section{A base de fontes}

A documentação da Legação brasileira em Berlim encontra-se no Arquivo Histórico do Itamaraty, no Rio de Janeiro, abrangendo toda a correspondência da Legação com o Ministério das Relações Exteriores do Brasil no Rio de Janeiro e outros órgãos governamentais brasileiros, a correspondência do Ministério das Relações Exteriores, do assim chamado Ofício Externo (Auswärtiges Amt) da Alemanha, a correspondência interna entre as representações brasileiras no território alemão (consulados gerais, consulados honorários), além de cartas, estatísticas, relatos e informações variadas. Dentro desse acervo, os relatos regulares da Legação, ou seja, do respectivo ministro plenipotenciário, chamam a maior atenção.

Uma das funções principais de qualquer representação brasileira no exterior foi o envio regular de informações políticas e econômicas sobre o respectivo país anfitrião. As orientações do Itamaraty para este sistema institucionalizado de relatórios consulares datavam do início do século XX e sofreram reformas sob o ministro Otávio Mangabeira (1886-1960, ministro das Relações Exteriores de 1926 a 1930) no governo de Washington Luís, destacando, especialmente, “[...] os três grandes assuntos nacionais: comércio exterior, crédito externo e imigração" (CERVO; BUENO, 2011, p. 248). Enquanto os diplomatas brasileiros no mundo inteiro receberam, "diariamente, dados sobre resoluções do governo e ocorrências nacionais relevantes" (CERVO; BUENO, 2011, p. 249), os embaixadores e chefes de legações, conforme essas reformas:

[...] deveriam, em vez de relatórios trimestrais, enviar mensalmente exposição sobre o que fosse observado no interesse da agricultura, comércio 
e indústria nacionais. Além disso, deveriam elaborar relatórios semestrais para publicação no Diário Oficial, do qual se extrairiam separatas para maior circulação, até então, os relatórios consulares eram publicados no Boletim do Ministério, sem a divulgação desejável. (CERVO; BUENO, 2011, p. 249).

Divergindo um pouco dessas orientações, que destacaram mais questões do comércio e dos negócios, os relatórios em questão informaram o Itamaraty, de forma extensa e detalhada, sobre a situação política da Alemanha. O conteúdo desses relatórios não apenas descrevia condições gerais da política mas também fatos e acontecimentos específicos, como: eleições para o Reichstag; mudanças nos governos do Império Alemão (Deutsches Reich), seja na última fase da República de Weimar, seja no início do regime nazista; sessões plenárias da Dieta Imperial (Reichstag); manifestações e protestos nas ruas da Alemanha; a ascensão de Adolf Hitler (1889-1945), o assim chamado Führer do Partido NacionalSocialista dos Trabalhadores Alemães (NSDAP); pronunciamentos dele; as novas leis decretadas no início do regime nazista, para transformar a República em uma ditadura, consolidar o poder nazista e pôr a ideologia autoritária, nazista e racista em prática; o falecimento (no dia 2 de agosto de 1934) e o enterro do presidente marechal Paul von Hindenburg (1847-1934), aproveitado pela máquina propagandística do regime nazista para encenar um espetáculo nacional, nacionalista e nacionalsocialista, e apresentar-se como representante legítimo da Alemanha.

Esses relatos tornaram-se ainda mais regulares sob o ministro plenipotenciário Artur Guimarães de Araújo Jorge (1884-1977), que substituiu, em outubro de 1933, Adalberto Guerra Duval. A partir de janeiro de 1934, nestes relatos consta como referência o termo Mêz político, dando informações no fim de cada mês sobre os acontecimentos do mês anterior - um corpo de fontes com uma grande autenticidade. ${ }^{1}$

As informações históricas sobre política, sociedade e economia da Alemanha no início dos anos de 1930, contidas nas fontes primárias selecionadas como base deste artigo, são múltiplas e variadas, fornecendo uma quantidade enorme de pormenores interessantes e, às vezes, pouco conhecidos, permitindo que se conheça um pouco mais de dentro a prática política e diplomática da época. Nesses relatos diplomáticos, reflete-se a realidade histórica; porém, em um olhar de um estrangeiro, de uma pessoa de fora, ou seja, em uma ótica tropical de um diplomata brasileiro. É interessante observar as peculiaridades da percepção específica de um cidadão brasileiro, socializado em um contexto diferente, das realidades alemãs, as suas escolhas, os seus recortes e destaques. Esse olhar tropical traz uma perspectiva nova sobre assuntos da história alemã suficientemente conhecidos.

Neste artigo vou focalizar outro aspecto do trabalho da Legação brasileira em Berlim: o dia a dia diplomático desta representação brasileira na Alemanha no início dos anos de 1930, quando a República de Weimar foi transformada na ditadura nazista.

Quais são as funções concretas de um diplomata no exterior? Quais são os seus trabalhos regulares e comuns? Os representantes diplomáticos são associados, comumente, com negociações importantes de tratados de paz, acordos de aliança ou tratados comerciais. O perfil de um diplomata, porém, não se restringe somente a essas atividades. O cotidiano dele é caracterizado por obrigações consulares, administrativas e burocráticas - nem sempre emocionantes e de grande prestígio. Com base nas fontes primárias selecionadas, este artigo pretende colocar em foco, no exemplo da Legação brasileira em Berlim, essa parte geralmente mais oculta das competências confiadas a representantes diplomáticos, parte esta que chama, evidentemente, menos atenção pública, mas forma a base firme nas relações entre dois Estados.

\section{Propostas de reformar o sistema consular do Brasil na Alemanha}

Com base na sua longa experiência no serviço diplomático brasileiro em geral e no seu posto na Legação brasileira em Berlim, o ministro plenipotenciário Adalberto Guerra Duval 
apresentou, no dia 21 de julho de 1931, as suas ideias sobre uma representação melhor do Brasil na Alemanha. Essa iniciativa tinha a ver, certamente, com as reformas administrativas que se realizaram no Ministério das Relações Exteriores no início do governo de Getúlio Vargas (CERVO; BUENO, 2011).

Adalberto Guerra Duval (1872-1947) havia sido nomeado ministro plenipotenciário brasileiro em Berlim por um decreto do dia 3 de março de 1920. Nascido em Porto Alegre e formado na Faculdade de Direito em São Paulo, ele ingressou, em outubro de 1895, no serviço diplomático, recolhendo muita experiência em diferentes cargos e em vários lugares do mundo, especialmente na América Latina (Assunção, no Paraguai, e Buenos Aires, na Argentina) e na Europa (São Petersburgo, na Rússia; Lisboa, em Portugal; Londres, no Reino Unido; e Haia, nos Países Baixos). Como ministro plenipotenciário, Adalberto Guerra Duval tomou posse do cargo em Berlim, em meados de maio de 1920, tornando-se o primeiro representante brasileiro na Alemanha após a ruptura das relações diplomáticas entre os dois países no decorrer da Primeira Guerra Mundial (1914-1918). Nomeado inicialmente de forma interina, ele ficou no cargo até setembro de 1933 - com breves interrupções: entre julho de 1925 e janeiro de 1926, quando ele tirou férias extraordinárias; entre janeiro e maio de 1926, quando ele esteve em comissão na capital do Rio de Janeiro; e entre abril e outubro de 1932, por razões desconhecidas. Adalberto Guerra Duval foi destituído do seu cargo em Berlim em outubro de 1933, provavelmente no contexto das mudanças regulares do pessoal diplomático. $\mathrm{Na}$ sua carreira diplomática, seguiram mais duas etapas: em setembro de 1933, Duval foi transferido para Lisboa e, em novembro de 1935, de lá para Roma, na Itália, onde ele se aposentou em 1939, segundo consta no Dicionário Histórico-Biográfico-Brasileiro (DHBB, 2010). Por mais de 12 anos, Duval representou o Brasil na Alemanha, conhecendo muito bem tanto a situação política e econômica do país, com a complicação pós-guerra, como os problemas da representação diplomática brasileira em um país com fortes tradições federativas.
As propostas de Duval dirigiram-se ao novo Ministro de Estado das Relações Exteriores, Afrânio de Melo Franco (1870-1943), que havia assumido o cargo no dia 24 de outubro de 1930. Jurista, diplomata e político, o mineiro Afrânio de Melo Franco, partidário da Aliança Liberal, apoiando o gaúcho Getúlio Vargas (1882-1954), foi nomeado ministro nas perturbações da Revolução de 1930, quando o presidente Washington Luís (1869-1957) foi deposto por um golpe militar. Uma junta militar provisória assumiu o governo, antes de passar o poder a Getúlio Vargas, que manteve Melo Franco no seu posto até o fim de dezembro de 1933 (DHBB, 2010). Nove meses após as transformações revolucionárias no Brasil, quando o governo Getúlio Vargas havia se consolidado, o chefe da Legação brasileira em Berlim viu o momento adequado para apresentar as suas propostas de reformar o sistema das representações consulares brasileiras na Alemanha.

A Allemanha, paiz onde a centralização administrativa ainda está por fazer, é antes um agglomerado de estados do que verdadeiramente um só estado. Pela sua extensão, pela diversidade das regiões que o constituem, o Reich offerece ás Missões Diplomaticas, como a nossa, um campo de acção especial que, talvez, não encontre semelhante senão nos Estados Unidos. Aqui caberia, para maior efficiencia, um regimen peculiar, em que a actividade do Chefe da Missão pudesse, a todo o tempo, multiplicar-se pelo orgão de agentes consulares bem escolhidos, habilmente escalados nos postos de maior interesse para o Brasil e bem relacionados nos districtos da sua residencia. (AHI, 1931). ${ }^{2}$

Perante as tarefas consulares sempre mais diversas e variadas, o sistema de Consulados honorários brasileiros, instalado, antigamente, de forma apressada e provisória, não ou somente mal correspondeu às exigências atuais. Os Cônsules não foram suficientemente qualificados ou perseguiram somente os seus próprios interesses. "Mas ainda assim", continuou o ministro plenipotenciário,

[...] seria injusto negar os serviços por elles prestados ao Brasil, serviços de pequena monta cada um delles, mas 
muito repetidos e quasi indispensaveis; serviços que a Missão Diplomatica teve de reclamar, com frequencia, sob a especie de informação urgente de proteção directa a compatriotas ou de intervenção officiosa e immediata junto a autoridade locaes. (AHI, 1931).

Esse aparelho de consulados honorários foi - também por razões financeiras e estruturais - reorganizado pelo Ministério das Relações Exteriores, ou, em outras palavras, cortado e suprimido, sem solicitar um parecer da Missão brasileira em Berlim. "Hoje", isto é, em julho de 1931, resumiu Duval:

[...] temos em todo o Reich cinco Consulados: em Hamburgo, em Bremen e os outros tres na Prussia e terras por elle administradas. $\mathrm{Na}$ Baviera, na Saxonia, na Thuringia, no Wurttenberg, no Hannover, na Silesia, na Pomerania emfim em todos os outros estados allemães não ha um agente consular do Brasil, que seja fonte de informação e orgão de propaganda; que dispense apoio aos brasileiros itinerantes; que transmitta á Legação noticias e esclarecimentos commerciaes de tanta valia neste momento. (AHI, 1931).

Adalberto Guerra Duval criticou fortemente na sua carta essa distribuição atual dos consulados honorários brasileiros na Alemanha, considerando-a:

[...] prejudicial aos nossos interesses. Vastas zonas de significação industrial e economica indiscutivel ficaram totalmente abandonadas, fóra de alcance dos nossos raros agentes actuaes, externas á sua actividade, alheias ás nossas possibilidades e inacessiveis á nossa propaganda, isto é, voluntariamente por nós offerecidas aos nossos concorrentes. (AHI, 1931).

Por outro lado, houve na Região de Renânia e do Ruhr dois consulados em um espaço estreito, localizados em Wuppertal e Colônia, ou seja, a uma distância de $45 \mathrm{~km}$. Foi por essa razão que Duval chegou à conclusão de que "[...] o Consulado de Colonia é despesa sumptuaria” (AHI, 1931).
$\mathrm{Da}$ mesma maneira, as associações industriais e comerciais alemãs (Frankfurt, no Rio Meno, Leipzig, Dresden, em Berlim) reclamaram a falta de representações brasileiras em todas as regiões da Alemanha e haviam se dirigido à Legação, "[...] para esclarecer o Governo Brasileiro da urgencia de reinstalar pelo menos alguns dos antigos Consulados honorarios" (AHI, 1931).

Nesse pano de fundo, Duval defendeu:

[...] o estabelecimento de agentes consulares nos grandes centros allemães de actividade economica e politica como, por exemplo: Frankfort, Munich, Sttutgard [sic!], Leipzig e Breslau. A exiguidade das verbas disponiveis não contraria a existencia util de consules honorarios, que nada impede que sejam absolutamente gratuitos e produtivos, se forem bem escolhidos. Sem qualquer proveito de remuneração pecuniaria, atrahidos mormente pela seducção e prestígio do cubiçado titulo de consul, encontrarei neste paiz, facil escolha de pessoas idoneas interessadas sinceramente em bem servir que, bem iniciadas, se tornarão optimas fontes de informação e propaganda. (AHI, 1931).

Assim, a escolha dos novos cônsules deveria ser atribuída, diretamente, à Missão Diplomática em Berlim. Mais informações sobre esse assunto não foram encontradas no Arquivo Histórico do Itamaraty.

Pouco mais de dois anos depois, obviamente sem qualquer relação a essa iniciativa, Adalberto Guerra Duval foi destituído do seu cargo de ministro plenipotenciário e substituído, em outubro de 1933, por Artur Guimarães de Araújo Jorge (1884-1977), que permaneceu em Berlim até fevereiro de 1935 (DHBB, 2010). Por uma carta extraordinária do dia 9 de setembro de 1933, assinada em nome do Ministro de Estado das Relações Exteriores pelo SecretárioGeral Felix de Barros Cavalcanti de Lacerda (18801950), a Legação brasileira em Berlim foi informada sobre essa mudança na sua direção.

Artur Guimarães de Araújo Jorge, enviado extraordinário e ministro plenipotenciário, tomou posse oficialmente em outubro de 1933 (DHBB, 2010). No dia 6 de outubro de 1933, o novo ministro 
plenipotenciário informou o Itamaraty no Rio de Janeiro sobre a sua chegada, em companhia da sua família, em Hamburgo, de onde ele dirigiu-se, imediatamente, para Berlim. No dia 16 de outubro de 1933, ele foi recebido pelo ministro alemão das Relações Exteriores, Barão Konstantin von Neurath (1873-1956, Ministro das Relações Exteriores de 1932 a 1938). Este agendou uma audiência com o presidente Paul von Hindenburg para o dia 18 de outubro de 1933, "[...] para a entrega de minhas credenciais e da revocatoria do meu antecessor" (AHI, 1933), como o diplomata relatou. De acordo com o que ele continuou relatando em sua carta ao Rio de Janeiro, a cerimônia realizou-se na quartafeira, 18 de outubro de 1933, às $12 \mathrm{~h}$,

[...] com a costumada solenidade. Terminados os discursos, o Presidente von Hindenburg, acompanhado de seu Ministro das Relações Exteriores e de altos funcionarios de sua casa civil, entreteve comigo, como é de estylo, uma rapida palestra, informando-se com interesse do Brasil, de sua situação politica e fazendo uma referencia especial á obra de aproximação entre os dois paizes realizada ultimamente pelas viagens do ‘Graf Zeppelin'. (AHI, 1933).

A partir daí, Artur Guimarães de Araújo Jorge representou o Brasil na Alemanha como o mais alto diplomata do seu país.

O Corpo Diplomático estrangeiro com sede em Berlim consistia, em outubro de 1933, como o novo ministro plenipotenciário relatou naquela oportunidade, ao todo de 50 representações: nove delas foram embaixadas, 35 legações ou missões, dirigidas por um enviado extraordinário e ministro plenipotenciário, como foi o caso da representação dos Estados Unidos do Brasil, quatro dirigidas por encarregados de negócios efetivos e duas por encarregados de negócios interinos. Duas vezes por ano, nos meses abril e outubro, listas atualizadas do corpo diplomático foram publicadas.

\section{Emigração para o Brasil}

No fim da República de Weimar, quando a crise político-econômica na Alemanha estava se agravando, houve várias iniciativas de emigração - para o Leste da Europa, para a América do Sul e também para o Brasil (MAINKA, 2008). No dia primeiro de julho de 1932, o Ministério das Relações Exteriores do Brasil foi avisado da chegada de 400 colonos alemães luteranos da Rússia, "procedentes do campo de refugiados de Cherbin" (AHI, 1932; GERTZ, 2010).

Esse projeto de emigração foi organizado e coordenado por uma associação protestante de caridade. Os migrantes viajaram pelo vapor Lipari da Companhia Chargeura Reunis via porto de Marselha, onde foram inspecionados pelo Coronel Gaelzer Netto, um funcionário do Serviço de Imigração, e receberam equipamentos necessários para a sua futura vida pelos representantes da associação Irmãos dos Pobres.

A pedido do coronel Gaelzer Netto, a Legação brasileira em Berlim acompanhou, junto com a Embaixada brasileira em Paris e o Consulado Geral brasileiro em Marselha, todo o empreendimento, "para que nenhum obstaculo ou difficuldade fosse creado a essa emigração” (AHI, 1932).

O Professor Ulmer falou aos refugiados sobre a importancia daquella Associação de que fazem parte todos os allemães protestantes da Allemanha, da America do Norte e de muitos outros paizes. (AHI, 1932).

O destino destes migrantes alemães foi o estado Santa Catarina, no Sul do Brasil.

Financiado foi este projeto pela "Associação Auxiliar", que pagou aproximadamente 70.000 marcos para o transporte, pela associação alemã Brüder in Not [Irmãos dos Pobres] com 3.000 dólares, a Cruz Vermelha da Alemanha com 4.500 dólares, e as duas igrejas protestantes dos PaísesBaixos, que contribuíram com 8.000 dólares, e 2.000 peças de roupas. A associação mundial protestante prometeu 25.000 marcos para a instalação dos imigrantes no Brasil, "[...] e o Dr. Lange se propõe de contribuir com seus se(r)viços gratuitos durante um anno nas questões economicas e technicas de sua especialidade" (AHI, 1932).

A comunicação entre as repartições participantes da Alemanha e do Brasil nem sempre foi fácil - devido a questões burocráticas 
e formais. Após telefonemas entre o Ministério alemão das Relações Exteriores com a Legação brasileira em Berlim e o Coronel Gaelzer-Netto do Serviço de Imigração, propôs o Ministério alemão, de forma escrita, à Missão brasileira entrar em contato telegráfico com o Ministério brasileiro de Relações Exteriores no Rio de Janeiro e solicitar um telefonema para a Legação brasileira em Shanghai, mandando " $[. .$.$] expedir visas gratúitas para os$ bielorussos de origem alemã que pretenderam emigrar de Shanghai e partir para o Brasil - cerca de 260 homens" (AHI). ${ }^{3}$ A nota verbal do Ofício externo alemão explicou:

A urgência do caso é exigida pela data da saída, determinada pela Liga das Nações (Ofício de Nansen) pelo vapor 'Porthos' da companhia Massageries Maritimes no dia 3 de abril de $1934{ }^{4}$ (AHI, 1932).

Em junho de 1935 e, de novo, em agosto do mesmo ano, a empresa de transporte - a Companhia de Navegação Lloyd Brasileira - pediu a despensa de certos requisitos feitos pelo governo da Alemanha a "[...] companhias estrangeiras que exploram o transporte de emigrantes de nacionalidade allemã,, entre outros "o deposito de RM 50.00" (AHI, 1932/1933). O Ministério das Relações Exteriores pediu à Legação em Berlim:

Sendo este assumpto de grande interesse para aquella Companhia de Navegação brasileira, peço a Vossa Senhoria o obsequio de o estudar com o mais cuidado de modo a poder apresental-o ao governo allemão sob um aspecto que torne possivel a solução que deseja a referida Companhia. (AHI, 1932/1933).

Não consta nas atas da Legação brasileira em Berlim se a sua interferência foi bem-sucedida.

\section{O cotidiano diplomático: a emissão de vistos e novos passaportes}

As questões práticas da emigração competiam, em geral, ao Consulado Geral brasileiro em Berlim que funcionava ao lado da Legação brasileira em Berlim até fevereiro de 1934.
Por uma decisão do Governo Provisório do Brasil, este Consulado foi extinto no dia 23 de fevereiro de 1934. O cônsul-geral, Sylvio Romero Filho, entregou ao ministro plenipotenciário Artur Guimarães de Araújo Jorge o arquivo e o mobiliário do Consulado. As funções consulares foram assumidas pelo primeirosecretário, Adriano de Sousa Quartin, que exerceu na Legação por seis meses também as tarefas do segundo-secretário, "[...] ajudado provisoriamente, conforme instrucções dessa Secretaria de Estado, dos auxiliares Raul Ribeiro da Silva e Ruy Vianna Bandeira" (AHI, 1934). O expediente consular foi transferido para a Legação e inaugurado no mesmo dia, em 23 de fevereiro de 1934,

[...] um pouco desordenadamente, em vista de serviço acumulado durante dias em que o Consul Geral procedeu ao inventario e regularização da correspondencia e da demora da entrega de carimbos com dizeres novos que tive de mandar fazer para a legalização dos varios documentos. (AHI, 1934).

Os horários de funcionamento foram todos os dias úteis, de 14 às 16 horas. Do secretáriogeral do Itamaraty no Rio de Janeiro o ministro plenipotenciário solicitou "normas uniformes" e um regulamento para o funcionamento deste expediente consular.

Enquanto um funcionário do Consulado Geral extinto, de nome Torres, já voltou para Hamburgo, reassumindo o cargo de cônsul adjunto lá, e outros dois funcionários, a saber, Raul Ribeiro da Silva e Ruy Vianna Bandeira, "foram designados para servirem provisoriamente no departamento consular da Legação" (AHI, 1934), solicitou o ministro plenipotenciário, no dia 20 de março de 1934, ordens concretas a respeito do antigo cônsul Sylvio Romero Filho. Mais informações sobre Sylvio Romero não foram encontradas.

Após a extinção do Consulado Geral, o expediente consular foi assumido pela própria Legação. Assim a Legação brasileira relatou ao Ministério no Rio de Janeiro sobre os nomes e números dos vistos expedidos: a Relação dos estrangeiros que seguiram para diversos Estados do Brasil e cujos passaportes foram visados pelo 
extinto Consulado Geral e pelo Serviço Consular desta Legação, durante o mez de Março de 1934 abrangeu 51 pessoas; entre elas, encontraram-se muitas com nomes de origem judaica. Ao longo de 1934, foram 72 pessoas em abril, 55 pessoas em maio, 85 pessoas em junho, 110 pessoas em julho, 67 pessoas em agosto, 90 pessoas em setembro, 87 pessoas em outubro, 57 pessoas em novembro e 62 pessoas em dezembro. Entre abril e dezembro de 1934, foram ao todo 685 pessoas que deixaram a Alemanha e emigraram para o Brasil.

A Missão brasileira em Berlim apoiou também cidadãos brasileiros para retornar para a sua pátria, como no caso da Senhora Carporina de Araújo Corrêa e dos seus dois filhos, que voltou via Hamburgo com um navio da Companhia Hamburgueza de Navegação, como consta em um relato da Legação do dia 25 de outubro de 1934.

$\mathrm{Na}$ medida em que as perseguições da população alemã se agravaram, com base na legislação discriminatória e racista, o governo alemão exigiu uma identificação mais inequívoca dos diplomatas estrangeiros e dos seus familiares. Devido a certos acontecimentos, "[...] nos quais diplomatas estrangeiros apesar de apresentar os seus passaportes não foram reconhecidos como tães e sofreram inconveniências" (AHI, 1934), surgiu a necessidade de conceder aos diplomatas e a seus familiares novos passaportes diplomáticos de cor vermelha. Assim, essas pessoas poderiam ser identificadas, de forma mais fácil, pela polícia e por outros órgãos de fiscalização, em contraste com outros estrangeiros. O Ofício Externo alemão solicitou a todas as representações diplomáticas que enviassem, tão logo possível, fotografias das pessoas em questão, para expedir os novos passaportes.

\section{Entrevista do embaixador brasileiro Adalberto Guerra Duval (abril de 1933)}

No dia 22 de abril de 1933, o chefe da Legação brasileira em Berlim e ministro plenipotenciário, Adalberto Guerra Duval, relatou ao Ministério no Rio de Janeiro, não sem satisfação e orgulho, sobre uma solicitação de um jornal nazista por uma entrevista: "Solicitado insistentemente pela redação do Angriff, jornal do Ministro da Propaganda, Senhor (Joseph) Goebbels (1897-1945), concedi a esta gazeta uma interview" (AHI, 1932/1933). ${ }^{5}$

O jornal Der Angriff, fundado em 1927, foi o órgão publicitário do Partido NacionalSocialista dos Trabalhadores Alemães (NSDAP) de Berlim e foi editado até o fim de outubro de 1933 pelo próprio Joseph Goebbels (LEMMONS, 1994). Elogiado e aplaudido por Goebbels e outros membros do governo, Duval teve certeza que a sua entrevista "[...] parece ter causado bôa impressão e foi reproduzida em varios jornais dos estados" (AHI, 1932/1933).

A concessão de uma entrevista pelo ministro plenipotenciário do Brasil foi interpretada, em um texto introdutório, como sinal de reconhecimento pelo governo brasileiro do "Governo (alemão) da Revolução nacional” (AHI, 1932/1933) e disposição de cooperar com este novo governo em Berlim.

Em um primeiro momento, esteve no foco da entrevista a situação política atual do Brasil após a Revolução Constitucionalista de 1932 (FEIJÓ; GERTEL, 1998).

A paz interior está restabelecida desde Outubro. São Paulo retomou, com animo e efficiencia, o seu trabalho productivo. $\mathrm{Na}$ evolução revolucionaria que se opera entre nós, o levante de São Paulo assigualou um momento grave, mas talvez como em certos processos curativos uma crise salutar. No entretanto, a rotação dos acontecimentos no Brasil é rapidíssima e a revolta de 9 de julho já é coisa do passado. Hoje, homens representativos redigem um projecto de constituição; o alistamento eleitoral vae-se fazendo sob a lei nova; as eleições para a Constituinte estão marcadas para 3 de Maio e a magna assemblea se installará, provavelmente, no primeiro do $2^{\circ}$ semestre d'este anno. Com tudo isto, não quero dizer que a actividade politica se tenha academicamente canalizado em discussões de paragraphos e artigos d'um frio texto constitucional. Como prova de vitalidade civica, se encachoeiram e espuman [sic!] as diversas correntes políticas, que foram alliadas na revolução de 1930 e, hoje, se disputam o passo. Cada grupo pretende sinceramente tentar o milagre que os outros companheiros da jornada de Outubro não puderam ainda realizar. 
Este é o maior perigo que ameaça as revoluções triumphantes. Todos nós exigimos dos chefes um prodigio divino, que redime, em alguns dias, os effeitos dos annos accumulados durante dezenas d'annos! E, infelizmente, ninguem faz. (AHI, 1932/1933).

Perguntado sobre a situação econômica e política da América do Sul, especialmente quanto à "expansão do bolchevismo" (AHI, 1932/1933), Duval deu a seguinte resposta:

No seu aspecto moral, politico e economico, a febre da America do Sul é um symptoma do estado geral do Mundo. Antes de tudo é uma crise do ideial [sic!]. A Europa era para os Sulamericanos o modelo de perfeição juridica, de ordem, de equilibrio politico e economico. A situação instavel, porque illogica, imposta no Velho Continente pelos effeitos da Grande Guerra, seguiu a sua marcha fatal até o demoronamento do edificio economico. O terremoto attingiu até os Estados Unidos. E o desequilibrio social e cataclysmo economico sacudiram os fundamentos da confiança sulamericana nas soluções européas d'apos guerra. Nós, que somos mocidade das nações, estamos, como a mocidade de hoje, á procura do novo ideial [sic!]. Quanto ao Brasil na nossa historia que entra pela gloriosa legenda de Portugal; na fibra da nossa raça que o sol caldeou e o ambiente americano renovou e refinou; no nosso humanitario conceito juridico; na nossa grande potencialidade economica, ha estofo bastante para talhar Ideial [sic!] brasileiro que não peça emprestado a ninguem umas ennevoadas ideologias contra a natureza, nem pretenda transplantar d'outras terras e d'outras circumstancias formulas livrescas d’economia social, que não se aclimatariam nunca no nosso solo, tam vasto e tam fertil, que pode nutrir 200 milhões de homens. (AHI, 1932/1933).

Com as suas alusões à mocidade do Brasil e às suas potencialidades, o diplomata Adalberto Guerra Duval antecipou, de certa forma, a perspectiva de Stefan Zweig (1881-1942), escritor austríaco perseguido pelo regime nazista e exilado, que deu, em 1941, ao seu livro eufemista sobre o Brasil, país que o havia acolhido no ano anterior, o título Brasilien. Ein Land der Zukunft (Brasil:
Um País do futuro) (ZWEIG, 1981a, 1981b) uma avaliação, válida ainda hoje. Aliás, também a previsão do crescimento da população, feita em 1933, não errou.

Quanto aos "novos perigos na America do Sul” (AHI, 1932/1933) e, se a Marinha e o Exército do Brasil conseguissem enfrentá-los, o ministro plenipotenciário respondeu que o Brasil, "onde não ha gente sem trabalho e ha ainda trabalho para muita gente, é um paiz pacifista” (AHI, 1932/1933), com Marinha e Exército bem instruídos; porém, não muito numerosos.

Sobre as relações entre a Alemanha e o Brasil, "sob o ponto de vista economico e intellectual" (AHI, 1932/1933), o ministro respondeu:

Sou grande admirador da cultura alleman, de seu methodo consciencioso e do seu genio de organização e procurei sempre estreitar cada vez mais as relações germano-brasileiras. Este tambem é o desejo do meu Governo que o põe em practica directamente com os 150 mil allemães que vivem no Brasil. Não conto, é claro, neste total de filhos de allemães, que são cidadãos brasileiros e amam a sua patria, nem esquecer a patria de origem. Nas colonias allemans ha escolas e egrejas proprias. O meu Governo nenhum embecilho oppõe a este culto de lembraça [sic!] practicado por leaes cidadãos brasileiros. Posso mais dizer que os descendentes dos immigrantes allemães contam-se entre os melhores filhos do Brasil. Eu mesmo que sou do Rio Grande do Sul onde se installou a maioria dos colonos allemães, posso em verdade affirmar-lhe as qualidades civicas e o ardente patriotismo brasileiro demonstrado pelos filhos de allemães'. D’outra parte devo notar que as relações economicas germanobrasileiras soffrem o contragolpe da inflação das tarifas alfandegarias, que tocam o extremo. E taes extremos são conselheiros perigosos. Diversas vezes já se lançou a ideia d'uma collaboração defensiva sulamericana. Dizem-me que o projecto reapparece agora. Mas, aqui, são estreitos o espaço e o tempo para penetrar neste assumpto, mesmo porque, hoje, quem disser coisas de simples bom senso sobre facilidades de intercambio e reciproco proveito de baixar barreiras de alfandega 
parecerá logo paradoxal e temerario. $\mathrm{Eu}$, entretanto, estou convencido de que, como o exagero da inflação da moeda trouxe fatalmente a restauração do standard ouro, assim tambem os excessos de tarifas e pautas aduaneiras sobre productos principaes reagirão em favor da livre troca d'estas mercadorias, reservando a tributação de intuito fiscal, ou protector, sómente aos artigos de segundo plano, isto é, áquelles cuja produção é possivel em quasi toda a parte, sem grande differença de preço de custo, ou qualidade, d'um paiz e outro. (AHI, 1932/1933).

Tais considerações econômicas, feitas pelo diplomata Duval, parecem ter sido feitas na discussão atual sobre o comércio internacional e as tarifas alfandegárias, patente é a sua atualidade.

Ao se despedir do jornalista que fez a entrevista, o ministro plenipotenciário brasileiro exprimiu, de modo informal, como consta no seu relatório ao Ministério no Brasil, o seu respeito pela Alemanha da qual esperava muito para o futuro uma declaração que deveria ter agradado o ministro alemão de Propaganda Joseph Goebbels:

Ainda uma coisa. Quero dizer-lhe a minha sincera admiração pela Allemanha, pela sua nobre cultura, pela formidavel vitalidade do seu povo, a quem a nossa civilização tanto deve e de quem o mundo tem o direito de esperar ainda muito mais. (AHI, 1932/1933).

A máquina propagandística do regime nazista certamente aproveitou a simpatia do representante brasileiro para justificar as mudanças políticas realizadas na Alemanha, a fim de consolidar o regime nazista.

\section{O anticomunismo e as relações diplomáticas com a Rússia/União Soviética em Berlim}

$\mathrm{Na}$ correspondência entre a Missão Diplomática brasileira em Berlim e o Ministério das Relações Exteriores no Rio de Janeiro, o tema do comunismo e do anticomunismo ocupa muito espaço.
Na opinião de um dos agentes da Missão, a saber Sylvio Romero Filho, a Alemanha era "um dos principaes centros da acção communista" (AHI, 1931), assim ele pretendeu informar, regularmente, o governo brasileiro sobre

[...] os elementos perigosos á ordem publica ou nocivos aos interesses nacionaes" (AHI, 1931). Em uma carta de 26 de setembro de 1931, ele relatou que o Rio de Janeiro foi, naquele momento, "[...] o mais importante campo de propaganda bolshewista na America do Sul, sendo chefe dessa propaganda e organizador dos seus agentes Preestorka (?) Adolph que se acha naquela capital. (AHI, 1931)

Seguiram nesta carta e em outra carta do dia 5 de outubro de 1931 mais informações detalhadas sobre outros agentes, que já haviam estado no Brasil ou estavam partindo para lá, os seus passaportes falsos e suas malas.

Nem sempre as vidas diplomática e privada andam de mãos dadas. Os deveres de representar o Brasil no exterior poderiam complicar a vida pessoal do chefe da Legação e de sua esposa, que sempre tinham de considerar os costumes diplomáticos, as formalidades impostas às relações internacionais e os interesses do seu país, como exemplifica um incidente, ocorrido no ano de 1934, que se referiu a Artur Guimarães de Araújo Jorge (1884-1977). Como enviado extraordinário e ministro plenipotenciário, ele havia sucedido Adalberto Guerra Duval na direção da Legação brasileira em Berlim, tomando posse em outubro de 1933 (DHBB, 2010).

Com base em uma notícia publicada no Jornal do Brasil, do dia 27 de março de 1934,

[...] segundo a qual o Embaixador da Russia em Berlim e a Senhora Chintschuck teriam estado presentes a uma recepção oferecida nesta Legação ao Corpo Diplomatico e às autoridades alemães" (AHI, 1934)

O secretário-geral do Ministério das Relações Exteriores do Brasil, Felix de Barros Cavalcanti de Lacerda (1880-1950), solicitou esclarecimentos ao ministro plenipotenciário. Em uma carta do dia 7 de maio de 1934, ele explicou 
o caso, comentando que "a noticia telegrafica transmitida para o Rio de Janeiro contem uma parte de verdade" (AHI, 1934), mas também erros. De fato, o casal Chintschuck, embaixador e embaixatriz da Rússia, compareceram

[...] nesta data a esta Legação. Não é, porem, exato que se tratasse de uma recepção oficial oferecida ao Corpo Diplomatico e ás autoridades nacionaes alemães" (AHI, 1934).

Segundo o cerimonial alemão, somente embaixadores tiveram o direito de realizar - após a entrega das credenciais - uma recepção oficial para o corpo diplomático, "[...] que é oficialmente feita pelo Introductor Diplomático assistido por membros da Secção do Protocolo" (AHI, 1934), para se apresentarem aos colegas. Assim explicou Artur Guimarães de Araújo Jorge:

No caso em questão, minha senhora naquele dia recebia, como o faz uma vez por mez, as pessoas de suas relações. Os Embaixadores da Russia comparecendo a essa recepção informal, fizeram-no em carater particular e meramente pessoal; sua presença nesta Legação constituiu um ato de cortezia que eu, sem desprimor, não podia nem devia impedir ou evitar. (AHI, 1934).

Após o processo da sua acreditação diplomática em Berlim, o diplomata asseverou não ter visitado a Embaixada da Rússia,

[...] acentuando desta maneira a inexistencia de relações oficiaes entre nossos dois paizes; tambem minha senhora, pela mesma razão, não fez a visita de cortezia á Embaixatriz da Russia. (AHI, 1934).

Contudo, houve encontros mais ou menos frequentes na ocasião de festas e sociedades ou nas casas de outros diplomatas. Mesmo assim, Artur Guimarães de Araújo Jorge confessou que existiam "as melhores relações pessoais" com o casal russo, salientando que:

[...] a Embaixatriz da Russia é hoje a decana das senhoras do Corpo
Diplomatico por morte do General Kemaleddin Sami Pacha, desde 1924 Embaixador da Turquia na Alemanha, cuja senhora, a princeza Emineh, exercia até bem pouco tempo aquelas funções entre as damas do Corpo Diplomatico. (AHI, 1934).

Além desse caso concreto, o Ministério no Rio de Janeiro solicitou também informações gerais:

[...] sobre as praxes seguidas em Berlim 'no que concerne os convites oficiaes para recepções, visitas protocolares em relação ao pessoal da Legação (aliás Embaixada) da Russia, pelas missões dos paizes que se encontram na mesma situação do Brasil, isto é, sem terem reconhecido o atual Governo sovietico. (AHI, 1934).

Os representantes destes países, seguindo informou o enviado extraordinário e ministro plenipotenciário do Brasil, também não realizaram, após o ato de acreditação, as suas visitas oficiais na Embaixada russa para se apresentarem. Enquanto em Berlim esta regra protocolar e formal foi respeitada, em outras capitais europeias a prática diplomática não foi tão rígida.

Em Londres, por exemplo, a praxe permitiu que o ultimo Embaixador da Russia tenha feito sua visita oficial ao Embaixador Regis de Oliveira que a retribuiu no carater de Decano do Corpo Diplomatico naquela capital. (AHI, 1934).

O regulamento protocolar estabelecido, como acrescentou o diplomata no seu relatório, “[...] não inpede as relações pessoaes nem exclue o convivio em sociedade com os representantes da Russia” (AHI, 1934). Quanto às recepções gerais, em Berlim não existiam convites oficiais. E quanto às festas nacionais de cada país, "[...] habitualmente as Legações recebem nessa ocasião todas as pessoas, nacionaes e estrangeiras, que desejarem honral-as com sua visita" (AHI, 1934). Essas explicações de Artur Guimarães de Araújo Jorge destacaram um princípio fundamental na diplomacia moderna desde os seus primórdios, no Renascimento (MATTINGLY, 1964): a necessidade de manter contato com o outro, embora seja concorrente 
político ou econômico, e ainda que oficialmente os contatos sejam interrompidos.

\section{Questão de negócios de armamento}

Além da política anticomunista defendida tanto pelo novo governo nazista da Alemanha como pelo regime autoritário recém-instalado no Brasil, houve interesses comuns na área de negócios de armamento. Em junho de 1933, a empresa Louis Soest \& Co., com sede em Düsseldorf, na Alemanha, enviou um catálogo de máquinas de fabricação de canhões, por meio da Legação em Berlim, às repartições responsáveis no Brasil. No início de agosto de 1933, a chegada do catálogo foi confirmada, entregue ao Ministério de Guerra e ao chefe da Comissão de Estudos para a Indústria Militar Brasileira (AHI, 1913).

No dia 12 de janeiro de 1934, a Missão brasileira em Berlim informou o secretário-geral do Itamaraty, Felix de Barros Cavalcanti de Lacerda (1880-1950), sobre o envio de materiais bélicos. Foram embarcadas, no dia 29 de novembro de 1933, para o porto de Santos pelo vapor Monte Sarmíento, "[...] 4 caixas contendo estopim, consignadas á firma Juvenal Franco \& Cia. E 2 caixas do mesmo material consignadas a Rieckmann \& Cia" (AHI, 1934), como pelo vapor Holstein "[...] 5 caixas com 450 kilos de estopim branco e 920 kilos de estopim preto, consignadas a Zerrener, Bulow \& Cia Limitada" (AHI, 1934).

Além do comércio de armas e materiais bélicos, houve também um intercâmbio de militares e informações. A Comissão Militar brasileira com sede em Bruxelas, composta pelo general José Fernandes Leite de Castro e seis outros oficiais, visitou em maio de 1934 a Alemanha. Na ocasião, foi convidada pelo governo alemão, a primeira vez, em novembro de 1933 mediante a Embaixada alemã em Paris, representada pelo adido militar general E. Kuhlenthal, e, de novo, pelo ministro da Alemanha em Bruxelas.

Quando o general José Fernandes Leite de Castro informou a Legação brasileira em Berlim sobre a visita da Comissão Militar entre os dias 14 e 21 de maio de 1934, o ministro plenipotenciário ficou surpreso, pois a Legação não havia recebido até o fim de abril nenhuma notícia sobre isso. $O$ general pediu que a Legação informasse as repartições alemãs sobre a data exata da sua chegada em Berlim, a saber, o dia 14 de maio. Nesse dia foram agendados vários encontros dos oficiais com ministros alemães: às 12 horas com o ministro alemão das Relações Exteriores, Barão Konstantin von Neurath, depois com o ministro da Guerra, Werner von Blomberg (1878-1946), e, por último, com o ministro da Marinha.

Em seguida, iniciou o programa oficial de inspeção. Foram realizadas visitas nas empresas Loewe e Siemens em Berlim, no Centro de desenvolvimento e pesquisa militar em Kummersdorf, em Brandenburgo, e nas fortificações na costa do Mar do Norte em Wilhelmshaven, "para visitar", como consta no convite, estabelecimentos fabris e assistir a demonstrações do armamento da Reichswehr" (AHI, 1933). No dia 21 de abril, a Comissão Militar partiu para a Varsóvia, na Polônia.

De acordo com os relatos colhidos, sugerese que as expectativas dessa visita de inspeção da Comissão Militar brasileira não foram satisfatórias, pois o convite do governo alemão foi motivado, principalmente, pelo interesse em vender armas e materiais bélicos. O general confessou em frente ao ministro plenipotenciário:

[...] que tinha motivos para acreditar que o Governo alemão não tivera a iniciativa do convite dirigido áquela missão e que lhe parecia, ao contrario, haver este sido insinuado ás autoridades militares do Reich por um pequeno numero de industriaes, capitaneado por um certo Hermann Haupt, meio brasileiro, meio alemão, que o General conhecera no Brasil de longe no fornecimento de armas e munições ao nosso excercito. (AHI, 1934).

Em um jantar na Legação brasileira, o general Leite de Castro ainda disse "[...] não haverem essas visitas sob o ponto de vista militar correspondido á sua espectativa e á de seus oficiaes" (AHI, 1934). No seu relato ao Itamaraty, o ministro plenipotenciário Artur Guimarães de Araújo Jorge anotou, de certa forma satisfeito com este resultado 
decepcionante, "pareceu-me desde logo estranho" (AHI, 1934) que o governo alemão havia convidado a Comissão Militar, sem ter informado a Missão Diplomática brasileira. O diplomata e o general consentiram

[...] que o Senhor Hermann Haupt, desejoso de recomendar-se ainda mais a determinadas fabricas alemãs (das quaes sua firma no Rio de Janeiro, Haupt \& Cia, já representante), gestionou por sua conta, junto de algumas autoridades militares alemãs o convite a missão militar brasileira. (AHI, 1934).

Apesar dessa experiência negativa, a cooperação entre o Brasil e a Alemanha nas questões militares continuou. A pedido do Contra-Almirante Raul Tavares, Diretor da Escola de Guerra Naval, o Ministério de Estado das Relações Exteriores dirigiu-se, em fevereiro de 1935, à Legação brasileira em Berlim, solicitando o Regulamento do Curso de Altos Estudos Militares, em vigor na Academia de Guerra em Berlim, e "[...] igualmente - se houver - o Regulamento de um Curso semelhante da Marinha de Guerra" (AHI, 1934/1935). Quanto à organização e didática, os respectivos regulamentos da Alemanha, da França e dos Estados Unidos da América deveriam servir como modelos "[...] para a futura criação do Curso de Altos Estudos Navaes, no Brasil” (AHI, 1934/1935).

\section{Comércio e negócios}

A Legação brasileira em Berlim atuou na área do comércio entre o Brasil e a Alemanha como elo de negociação, estabelecendo contatos, mediando negócios e providenciando a realização prática deles. No início da década de 1930, a Legação participou, entre outras, de ações que envolveram a ratificação de um Tratado de Comércio entre Brasil e Alemanha.

Dessa forma, negociações longínquas sobre um Tratado de Comércio entre o Brasil e a Alemanha, iniciadas ainda nos tempos da República de Weimar, chegaram, finalmente, em novembro de 1933 a um termo. Esse tratado havia sido assinado, em 22 de outubro de 1931, no Rio de Janeiro. Após uma longa fase de verificação pelo governo alemão, o Ministério alemão das Relações Exteriores informou, no dia 3 de novembro de 1933, a Legação brasileira sobre o consentimento do governo do Reich. No dia 20 de novembro, o ministro plenipotenciário recebeu os documentos de ratificação pelo governo alemão do Acordo Comercial, entregando, por sua vez, a este os documentos ratificados pelo governo brasileiro. Com essa troca dos documentos de ratificação, o Acordo Comercial entrou em vigor no dia seguinte, $21 \mathrm{de}$ novembro de 1933, com a duração de dois anos.

Rubens Ricupero, no seu livro atual, $A$ diplomacia na construção do Brasil, 1750-2016 (2017), data esse Acordo Comercial de fins de 1934, “[...] antes do assinado com os Estados Unidos". O atrativo deste Acordo era, segundo Ricupero (2017, p. 327), "[...] poder escoar, graças aos preços mais altos oferecidos pelos alemães, produtos gravosos, isto é, cujo preço excedia as cotações internacionais". A Alemanha tornou-se mercado para algodão, produto crescente na agricultura brasileira como alternativa ao café, e

[...] para outros artigos produzidos em regiões politicamente influentes, sobretudo lã, couros, peles, tabaco e outras mercadorias do Nordeste e do Rio Grande do Sul. (RICUPERO, 2017, p. 327).

Enquanto a Alemanha serviu, quase que exclusivamente, como mercado para estes produtos, o Brasil resistiu até 1938 às reclamações dos Estados Unidos contra este Acordo, "[...] recorrendo a evasivas subterfúgios, promessas não cumpridas e, em certos casos, à negação do óbvio" (RICUPERO, 2017, p. 327).

Esse Acordo Comercial com a Alemanha não foi o único que o Brasil celebrou nesse período. Entre 1930 e 1933, quando Afrânio de Melo Franco foi Ministro das Relações Exteriores do Brasil,

[... 31 acordos comerciais com a cláusula incondicional e ilimitada de nação mais favorecida foram assinados. . "Em 1935, todavia, todos os tratados seriam denunciados pelo Brasil, quando constatou que seus parceiros comerciais, mormente os europeus, 
estavam recorrendo a uma série de artifícios para tornar sem efeito a cláusula de nação mais favorecida, praticando um protecionismo por métodos modernos. Aqueles tratados ficariam sem efeito na prática. (CERVO; BUENO, 2011, p. 257s.).

No final do ano de 1933, o Instituto de Mate do Estado do Paraná queixou-se dos efeitos negativos do aumento das taxas de entrada na Alemanha para a exportação desse produto. Em um ano apenas, a exportação do mate para a Alemanha caiu $80 \%$. No início do ano de 1934, o secretário-geral do Itamaraty, Cavalcanti de Lacerda, solicitou ao novo ministro plenipotenciário Artur Guimarães de Araújo Jorge

[...] examinar devidamente o assunto, procurando um possivel entendimento com esse governo no intuito de ser evitada a perda do mercado alemão, a produzir-se fatalmente, se prevalecer a politica aduaneira adotada; altamente nociva aos nossos interesses comerciaes. (AHI, 1934).

O Ministério brasileiro de Agricultura solicitou, em julho de 1934, dos Consulados brasileiros na Alemanha:

[...] a exportação de batatas para plantio no Brasil que devem preencher todas as formalidades constantes dos decretos $[\ldots]$, principalmente no que se refere $[\ldots]$ [à determinação] que exige seja cada partida acompanhada de um atestado expedido pelo Ministerio da Agricultura do paiz produtor, provando tratar-se efetivamente de tuberculos selecionados para semente. (AHI, 1934/1935).

Quando a Legação brasileira em Berlim enviou ao Itamaraty a proposta da empresa W. Godelmann de Berlim, de importar borracha do Brasil, o Ministério no Rio de Janeiro repreendeu, em dezembro de 1934, os diplomatas em Berlim, instruindo-os a não se intrometerem no comércio:

O Conselho Federal do Commercio Exterior declarou ser inaceitavel o systema de troca de productos, com intervenção do Governo, sendo apenas possivel a realização de operações pelos meios commerciaes privados, de accordo com a legislação vigente, processando-se por intermedio do mercado de cambio livre. (AHI, 1934/1935).

A empresa alemã foi direcionada às empresas brasileiras que atuavam nessa área. Resoluções semelhantes referiram-se à empresa Maschinenfabrik Otto Peron, de Berlim, que havia proposto "o estabelecimento de comercio de permutas entre o Brasil e a Allemanha" (AHI, 1931), e à firma Otto Behr de Bremen, que havia solicitado a importação de algodão do Brasil. Foi recomendado o seguinte procedimento:
Assim, poderão os interessados dirigir- se aos exportadores brasileiros, aos quaes comprarão as mercadorias, pagando-as em Reichsmarks a serem creditados ao Banco comprador das respectivas cambiaes, para applicação no pagamento de productos allemães no Brasil, não sendo necessaria a intervenção do Governo para que sejam respeitados e attendidos os objectos dos regulamentos allemães. (AHI, 1932).

Uma outra proposta da firma S. Wolle de Aue, de realizar "negocios de compensação com o Brasil" (AHI, 1933), foi negada, porque o Banco do Brasil havia informado "[...] não haver possibilidades de estabelecer um intercambio nestas condições, pois o Brasil faz troca directa de produtos" (AHI, 1934).

A Legação brasileira em Berlim apoiou empresas alemãs interessadas em negócios com o Brasil - como no caso da empresa Hoeffgen \& Co. de Berlim, que havia solicitado "[...] a exportação de minerios molibdeno, niquel e vanadio" do Brasil para a Alemanha e recebeu informações da Missão em Berlim sobre as possibilidades - ou estabeleceu várias vezes contatos com o Itamaraty para comerciantes alemães que viajaram para o Brasil, como no caso do empresário F. Rodenburg, que veio para o Brasil "[...] com o intuito de estimular o intercambio commercial com o Brasil” (AHI, 1933).

Quando o governo brasileiro deliberou estabelecer a livre concorrência entre as 
companhias de navegação, entrou o Verein der am Kaffeehandel beteiligten Firmen [Associação das Firmas Participantes no Comércio do Café] com uma solicitação ao Ministério da Fazenda, dirigido naquele momento pelo Ministro Osvaldo Aranha (1894-1960), contra as medidas pretendidas. $\mathrm{Na}$ opinião dos comerciantes, essas medidas seriam "contraproducentes e até prejudiciaes aos interesses brasileiros" (AHI, 1934), tornando absurdas as taxas de frete aos exportadores; assim, eles poderiam retirar-se do comércio com o Brasil, preferindo países com condições de transporte preestabelecidas e mais estáveis. Uma decisão sobre esse assunto não consta na documentação da Legação brasileira em Berlim.

\section{Intercâmbio científico e cultural}

A pedido da Legação brasileira em Berlim, de setembro de 1933, o Ministério alemão das Relações Exteriores providenciou amostras de trigo persa para o estado do Rio Grande do Norte. Encarregado pela Legação alemã em Teerã, o Diretório do Banque Agricole tentou conseguir amostras de trigo na Pérsia. Segundo uma nota verbal do Ministério alemão, do dia 21 de novembro de 1933, não foi possível obter amostras de trigo da Pérsia Meridional; faltava tempo para uma seleção correta e para verificar com todo o cuidado com a qualidade e a adequação ao clima e ao solo. Mesmo assim, acreditava-se "[...] que o cereal enviado da Pérsia Setentrional seria mais conveniente para as condições brasileiras de solo e clima do que o trigo da Pérsia Meridional"6 (AHI, 1933). Convicto de "[...] que a falta de sementes do sul da Persia em nada prejudicará os ensaios de cultura do cereal que pretende realizar o Governo do Rio Grande do Sul" (AHI, 1933), a Missão brasileira em Berlim pediu o pagamento das despesas de 156,96 marcos, que foi realizado somente em fevereiro de 1934.

Além dessa cooperação na realização de negócios, houve, de fato, um intercâmbio científico referente à pesquisa e ciência. Em setembro de 1933, a Legação brasileira foi informada pelo Ministério alemão das Relações Exteriores sobre a participação de um professor alemão em uma expedição para o
Brasil, organizada pela Dra. Wanda Hanke (18931958) em Viena, Áustria. Após estudos de psicologia, medicina e direito nas Universidades de Munique e Heidelberg, concluídos cada um pelo doutorado, Dra. Hanke havia aberto, em Viena, um consultório médico. Logo ela se dedicou à pesquisa etnológica dos indígenas sul-americanos, especialmente de suas línguas e religióes. Para o ano de 1934, ela preparou uma expedição para o Paraguai, a Bolívia e o Brasil Ocidental.

Dessa expedição participou o antropólogo alemão Dr. Johann Schäuble, do KaiserWilhem-Institut für Anthropologie [Instituto Imperador Guilherme para Antropologia], um de vários Institutos de Pesquisa, pertencentes à Kaiser-Wilhem-Gesellschaft zur Förderung der Wissenschaften [Sociedade Imperador Guilherme para Promover as Ciências], de certa forma uma sociedade antecessora da atual Max-PlanckGesellschaft [Sociedade Max Planck]. Como o Dr. Schäuble teve que partir já no dia primeiro de outubro de 1933, à Legação foi solicitado facilitar as formalidades. Quanto aos objetivos específicos dessa expedição, consta nesta carta:

A expedição depesquisa, tendo objetivos
etnológicos, psicológicos, geográficos e
antropológicos, parte no outono deste
ano da Europa, para realizar pesquisas
no Mato Grosso [em e no redor de
Cuiabá] e na região da nascente do
Rio Hindu. Quanto aos participantes
da expedição, provindo de Viena, o
governo brasileiro já foi informado
mediante a Legação austríaca no Rio de
Janeiro. $^{7}$ (AHI, 1933).

Em janeiro de 1934, o secretário-geral do Itamaraty, Cavalcanti de Lacerda, informou a Legação em Berlin, que o Ministério de Guerra havia comprado um livro manuscrito de um oficial alemão a serviço das tropas brasileiras na Guerra Cisplatina entre 1825 e 1828. Tratava-se dos Erinnerungen auf den Feldzug 1827 gegen Buenos Aires [Memórias da campanha de 1827 contra Buenos Aires] do Capitão e mais tarde Coronel Seveloh, servindo nas tropas de Felisberto Caldeira Brant, Marquês de Barbacena (MARTINS, 2009, p. 157). 
A Orquestra Filarmônica de Berlim realizou, no dia 25 de setembro de 1934, um concerto no salão de mesmo nome, como consta em um relato da Missão do dia 29 de setembro de 1934:

[...] sob a direção do maestro brasileiro Walter Burle Marx. [...] O numeroso publico que enchia o vasto salão da Philarmonia applaudiu calorosamente a execução dos varios numeros de programma e prodigalisou ao nosso compatriota no final do concerto uma prolongada e vibrante ovação: a imprensa de Berlim occupou-se largamente do concerto. (AHI, 1934/1935).

Artur Guimarães de Araújo Jorge avaliou o concerto, realizado sob o seu patrocínio, como "uma nota auspiciosa e lisongeira para os creditos da nossa cultura artistica" (AHI, 1934/1935). O programa do concerto não consta no relato diplomático, o ministro plenipotenciário informou, porém, que fez incluir,

[...] por uma deferencia especial a meu collega e amigo Eduardo Labougle, Ministro da Republica Argentina, um numero de musica do conhecido regente e compositor argentino Juan José de Castro. (AHI, 1934/1935).

Com muita satisfação ele relatou também da recepção solene na véspera deste concerto nas instalações da Legação,

[...] a que compareceram representantes de todos os jornaes desta capital, personalidades em voga nos circulos artisticos e musicaes, autoridades nacionaes, pessoas da sociedade e amigos do Corpo Diplomatico. (AHI, 1934/1935).

\section{Relações teuto-brasileiras - passado, presente e futuro}

Apesar da longa distância de quase 10 mil quilômetros entre o Brasil e a Alemanha, as histórias dos dois países apresentam, desde o século XVI, paralelas, convergências e conexões (pessoais), como comprovam os seguintes exemplos: no século $\mathrm{XVI}$, as viagens dos conquistadores Hans Staden (1525-1576) (STADEN, 2007) e Ulrico Schmidel (1510-1580) (SCHMIDEL, 2010) pelo território brasileiro; no século XVII, o governo de Johann Moritz von Nassau Siegen (1604-1679), a serviço da Companhia Holandesa das Índias Ocidentais no Nordeste do Brasil (BRUNN; NEUTSCH, 2008); no fim do século XVIII, os estudos de exploração de minas de José Bonifácio de Andrada e Silva (1763-1838), político da Independência do Brasil, na Academia de Minas em Freiberg/Saxônia, Alemanha (REIS, 2003); no século XIX, as viagens científicas de Carl Friedrich Wilhem von Martius (1794-1868), cientista natural, botânico e etnógrafo, e de Johann Baptist von Spix (1781-1826) (HELBIG, 1994; MACKNOW LISBOA, 1997), naturalista e zoólogo; e a imigração alemã, que continuou até o século XX, quando o Brasil tornou-se também um destino de salvação para perseguidos e fugitivos do regime nazista.

As relações mútuas entre os dois países se intensificaram nos últimos dois séculos, apesar de posições diferentes e até opostas nas relações internacionais - como na Primeira Guerra Mundial, quando o Brasil, no dia 5 de abril de 1917, após três anos de neutralidade, entrou na guerra contra a Alemanha (RICUPERO, 2017; CERVO; BUENO, 2011).

A política externa do Brasil na era Getúlio Vargas, posicionada entre a Alemanha e os Estados Unidos da América, foi interpretada pela historiografia posterior, segundo Rubens Ricupero, com fórmulas como "jogo duplo, diplomacia pendular, equidistância pragmática” (RICUPERO, 2017, p. 329). Esta perspectiva ex post procura, naturalmente, descobrir um sistema, uma estratégia calculada. O diplomata experiente Ricupero avalia essa aparente alternativa não como "uma real possibilidade de opção político-estratégica pelo nazismo alemão", mas como "oportunismo de explorar as chances de ganhos econômicos e comerciais, enquanto foi isso exequível" - antes do envolvimento dos EUA na Segunda Guerra Mundial. Nesse sentido, a futura política do Brasil no início da década de 1930, estando no foco deste artigo, 
ainda não foi determinada. Em outras palavras: a simpatia do governo de Getúlio Vargas, golpista e usurpador do poder, pela Alemanha, que estava a caminho de uma ditadura sob a direção de Adolf Hitler, foi autêntica e verídica - e se refletiu também na atuação da Legação brasileira em Berlim.

Houve uma cooperação normal e não declarada em várias áreas: em questões do comércio e dos negócios, na cooperação internacional e na ação conjunta das diplomacias brasileira e alemã. Exemplos dessa parceria são: a compra de trigo na Pérsia para o estado brasileiro do Rio Grande do Sul, quando as instituições diplomáticas alemãs, presentes na Pérsia, deram assistência à diplomacia brasileira; na cooperação militar, seja em relação à formação e qualificação dos militares, seja em negócios de armamento; no intercâmbio científico e cultural; e em uma política rigorosamente anticomunista, que se manifestou também em uma relação oficialmente distante - melhor dizendo, em uma não relação - com os representantes diplomáticos da União Soviética -, à custa das relações pessoais do ministro plenipotenciário do Brasil e de sua esposa.

Esse anticomunismo intransigente resultou, finalmente, na cooperação estreita dos órgãos da segurança pública do Brasil e da Alemanha, no que diz respeito à perseguição e à captura de comunistas e pretensos espiões comunistas. Isso selou o destino da comunista alemã Olga Benário (1908-1942), esposa de Luís Carlos Prestes (1898-1990), que foi capturada em março de 1936 pela polícia brasileira. Assim, em setembro de 1936, ela foi extraditada para a Alemanha, mesmo estando grávida, tendo no ventre uma cidadã brasileira, e foi assassinada, no dia 23 de abril de 1942, no campo de concentração alemão de Bernburg. Este último seria um exemplo extremo da cooperação estreita entre os dois governos brasileiro e alemão autoritários, recémchegados ao poder, e a conexão das histórias do Brasil e da Alemanha.

No início da década de 1930, enquanto os dois governos de Getúlio Vargas e Adolf Hitler ainda não tinham consolidado o seu poder e definido, categoricamente, os seus objetivos, surgiu por um momento a possibilidade de parceria internacional entre os dois Estados contra o fantasma comunista e em favor de uma política autoritária e nacionalista. No entanto, esse momento passou rapidamente. As expectativas econômicas que o Brasil havia depositado até 1938 na Alemanha não se realizaram: com a política brasileira de nacionalização, em detrimento dos colonos alemães no Brasil, emergiram tensões e atritos entre os dois Estados; além disso, o fato de que o governo nazista estava se preparando, sem quaisquer escrúpulos, para uma guerra, pôs fim definitivo a uma cooperação mais estreita. Finalmente, encontraram-se o Brasil, sob a forte pressão dos Estados Unidos, e a Alemanha em campos militares opostos na Segunda Guerra Mundial. Somente na época pós-guerra, os caminhos dos dois países tão distantes, de novo, aproximaram-se - ainda mais após a redemocratização do Brasil.

\section{Notas}

1 Devido ao alto caráter autêntico desses relatos políticos, contendo informações valiosas sobre a situação política na Alemanha na transição da República de Weimar para o regime nazista, pretende-se publicá-los, uma vez que são fontes contemporâneas, fornecidas por representantes oficiais, por um lado com uma perspectiva de fora, ou seja, distante e "tropical", mas que participaram, por outro lado, diretamente dos acontecimentos ou os observaram de perto.

2 A ortografia do português usada nos relatos da Legação brasileira em Berlim é diferente da atual. Assim nas transcrições das fontes primárias há, ao olhar do tempo atual, muitos termos escritos de forma diferente ou aparentemente errada. As normas da ABNT recomendam, em regra geral, que sejam marcadas essas variações da escrita pelo editor. Devido à quantidade enorme de termos escritos de forma diferente, renunciase, em seguida, à marcação dessas palavras, para não dificultar ou atrapalhar a leitura.

3 Citação no original: "Gratisvisa fuer die aus Shanghai abwandernden und sich nach Brasilien begebenden deutschstaemmigen Weissrussen - ca. 260 Menschen - zu erteilen" (AHI, 1932).

4 Citação no original: "Die Dringlichkeit der Angelegenheit ist bedingt durch die seitens des Voelkerbundes (Nansenamt) bestimmte Abreise mit Dampfer 'Porthos' von der Massageries Maritimes zum 3. April 1934” (AHI, 1932).

5 A entrevista foi publicada no dia 12 de abril de 1933 no jornal "Der Angriff". 
6 Citação no original: "[...] dass die uebersandte nordpersische Frucht fuer die brasilianischen Boden-und Klimaverhaeltnisse zweckmaessiger sei als suedpersischer Weizen" (AHI, 1933).

7 Citação no original: "Diee Forschungsreise, die ethnologische, psychologische, geographische und anthropologische Ziele verfolgt, verlaesst im Herbst dieses Jahres Europa, um im Matto Grosso [in und um Guyaba] und im Hinduquellgebiet Forschungen anzustellen. Fuer die aus Wien stammenden Teilnehmer der Expedition ist die Brasilianische Regierung bereits durch Vermittlung der oesterreichischen Gesandtschaft in Rio de Janeiro verstaendigt" (AHI, 1934/1935).

\section{Referências}

ARQUIVO HISTÓRICO DO ITAMARATY (AHI). Comunicações entre Ministério das Relações Exteriores e as embaixadas brasileiras no exterior, Rio de Janeiro (sem paginação ou foliação).

ARQUIVO HISTÓRICO DO ITAMARATY (AHI). Comunicações entre Ministério das Relações Exteriores e as embaixadas brasileiras no exterior, Berlim, Ofícios, 1931, estante 4, prateleira 2, maço 13 (AHI, 1931).

ARQUIVO HISTÓRICO DO ITAMARATY (AHI). Comunicações entre Ministério das Relações Exteriores e as embaixadas brasileiras no exterior, Berlim, Ofícios, 1932 (jan./set.), estante 4, prateleira 2, maço 14 (AHI, 1932).

\section{ARQUIVO HISTÓRICO DO ITAMARATY (AHI).} Comunicações entre Ministério das Relações Exteriores e as embaixadas brasileiras no exterior, Berlim, Ofícios, 1932 (out.) - 1933 (abr.), estante 4, prateleira, 2, maço 15 (AHI, 1932/1933).

\section{ARQUIVO HISTÓRICO DO ITAMARATY (AHI).} Comunicações entre Ministério das Relações Exteriores e as embaixadas brasileiras no exterior, Berlim, Ofícios, 1933 (maio/dez.), estante 4, prateleira 2, maço 16 (AHI, 1933).

ARQUIVO HISTÓRICO DO ITAMARATY (AHI). Comunicações entre Ministério das Relações Exteriores e as embaixadas brasileiras no exterior,
Berlim, Ofícios, 1934 (jan./jun.), estante 4, prateleira 3, maço 1 (AHI, 1934).

ARQUIVO HISTÓRICO DO ITAMARATY (AHI). Comunicações entre Ministério das Relações Exteriores e as embaixadas brasileiras no exterior, Berlim, Ofícios, 1934 (jul.)-1935 (mar.), estante 4, prateleira 3, maço 2 (AHI, 1934/1935).

ARQUIVO HISTÓRICO DO ITAMARATY (AHI). Comunicações entre Ministério das Relações Exteriores e as embaixadas brasileiras no exterior, Berlim, Ofícios, 1935 (abr./dez.), estante 4, prateleira 3, maço 3 (AHI, 1935).

BERTONHA, João Fabio. O Integralismo e sua história: memória, fontes, historiografia, Salvador: Pontocom, 2016.

BRACHER, Karl Dieter [1960]. Stufen der Machtergreifung (Bracher/Schulz/Sauer: Die nationalsozialistische Machtergreifung. Bd. 1). Frankfurt/Berlin/Wien: Verlag Ullstein, 1974.

BRUNN, Gerhard; NEUTSCH, Cornelius (Org.). Sein Feld war die Welt. Johann Moritz von Nassau-Siegen (1604-1679). Von Siegen über die Niederlande und Brasilien nach Brandenburg. Münster et al.: Waxmann, 2008.

CERVO, Amado Luiz; BUENO, Clodoaldo [1992]. História da política exterior do Brasil. 4. ed. rev. ampl. Brasília: UnB, 2011.

DICIONÁRIO HISTÓRICO-BIOGRÁFICO BRASILEIRO (DHBB). Centro de Pesquisa e Documentação de História Contemporânea (CPDOC) da Fundação Getúlio Vargas (FGV). DUVAL, Adalberto Guerra. 3. ed. atualiz., 2010. Disponível em: http://www.fgv.br/cpdoc/acervo/ dicionarios/verbete-biografico/duval-adalbertoguerra. Acesso em: 20 jul. 2018.

FAUSTO, Boris. A revolução de 1930. São Paulo: Brasiliense, 1982.

FEIJÓ, Martin Cezar; GERTEL, Noé. 1932: a guerra civil paulista. São Paulo: Ática, 1998. 
GERTZ, René E. Existem teuto-russo no Brasil?. In: DREHER, Martin N. (Org.). Migrações: mobilidade social e espacial. São Leopoldo: Oikos, 2010. p. 56-69.

GOMES, Marly de Almeida. Revolucionários de 35: sonhos e realidades. São Paulo: Companhia das Letras, 1992.

HARMS-BALTZER, Käte. Die Nationalisierung der deutschen Einwanderer und ihrer Nachkommen in Brasilien als Problem der deutsch-brasilianischen Beziehungen 1930-1938. Berlin: Colloquium Verlag, 1970.

HELBIG, Jörn (Ed.). Brasilianische Reise 1817 1820. Carl Friedrich Philipp von Martius zum 200. Geburtstag, München: Hirmer Verlag, 1994.

LEMMONS, Reussel. Goebbels and Der Angriff. Kentucky: University Press, 1994.

MACKNOW LISBOA, Karen. A nova atlântida de Spix e Martius: natureza e civilização na Viagem pelo Brasil (1817-1820). São Paulo: Hucitec, 1997.

MAINKA, Peter Johann. Roland und Rolândia im Nordosten von Paraná. Gründungs- und Frühgeschichte einer deutschen Kolonie in Brasilien (1932-1944/45). São Paulo: Cultura Acadêmica; Instituto Martius-Staden, 2008.

MARTINS, Ricardo André Ferreira. Atenienses e Fluminenses: Invenção do Cânone Nacional. 2009. 784 f. Tese (Doutorado em Teoria e História Literária) - Programa de Pós-Graduação do Instituto de Estudos da Linguagem, Universidade
Estadual de Campinas, Campinas, 2009. Disponível em: http://www.repositorio.unicamp.br/handle/ REPOSIP/269985. Acesso em: 13 ago. 2018.

MATTINGLY, Garrett [1955]. Renaissance Diplomacy. Baltimore: Penguin Books, 1964.

REIS, Fernando. Verbete "José Bonifácio de Andrada e Silva (1763-1838)". In: INSTITUTO CAMÕES. Ciência em Portugal: Personagens e Episódios. 2003. Disponível em: http://cvc.instituto-camoes. pt/ciencia/p18.html. Acesso em: 31 ago. 2018.

RICUPERO, Rubens. A diplomacia na construção do Brasil 1750-2016. Rio de Janeiro: Versal, 2017.

SCHMIDEL, Ulrich. Wahrhafte Historie einer wunderbaren Schifffahrt, welche Ulrich Schmidel von Straubing von 1534 bis 1554 in Amerika oder Neue Welt bei Brasilia oder Rio de la Plata gethan. Wiesbaden: Marix, 2010.

STADEN, Hans. Warhaftige Historia: zwei Reisen nach Brasilien (1548-1555)/História de duas viagens ao Brasil. Kritische Ausgabe. Hg. von Franz Obermeier. Kiel: Westensee-Verlag, 2007.

WINKLER, Hans-Ulrich. Weimar 1918-1933. Die Geschichte der ersten deutschen Demokratie. München: Verlag C. H. Beck, 1993.

ZWEIG, Stefan [1941]. Brasilien. Ein Land der Zukunft. Frankfurt am Main: Insel-Verlag, 1981a.

ZWEIG, Stefan: Brasil: País do futuro. Rio de Janeiro: Nova Fronteira, 1981b. 